\title{
Deep-sea megafaunal response to physical disturbance along the SW Portuguese continental slope
}

\section{Ramalho, S.P. ${ }^{1,2}$ Lins, L. ${ }^{2}$ Lampadariou, N. ${ }^{3}$ Vanreusel, A. ${ }^{2}$ Cunha, M.R. ${ }^{1}$}

\author{
${ }^{1}$ Departamento de Biologia \& CESAM, Universidade de Aveiro, Portugal \\ ${ }^{2}$ Marine Biology Research Group, Ghent University, Krijgslaan 281/S8, 9000 Ghent, Belgium \\ ${ }^{3}$ Hellenic Centre for Marine Research, Heraklion, Crete, Greece
}

Continental slopes support highly diverse ecosystems strongly influenced by habitat heterogeneity and increasing anthropogenic disturbance, of which bottom trawling fisheries are considered of major importance. Recent studies showed that megafauna assemblages are particularly sensitive to trawling disturbance in hard substrate habitats (e.g. seamounts) but impacts on soft sediments are mostly unknown. Video surveys obtained by Remotely Operated Vehicle (ROV) were used to investigate megafaunal structural and functional diversity in areas subjected to different degrees of disturbance (no, low and high trawl intensity) covering different soft sediment habitats (muddy-sand and sandy bottoms) along the SW Portuguese continental slope. In total, $17 \mathrm{~km}$ of video transects were analysed within a bathymetric range of $200 \mathrm{~m}$ and $700 \mathrm{~m}$ water depths. All disturbed areas displayed frequent and recent trawl marks (up to 3 marks per 100m), with general flattened seafloor topography and low bioturbation. Additional scattered litter presence was observed. Megafauna abundances were highly variable among habitats, revealing more than 80 morphospecies, belonging to 17 classes. Overall, communities from muddy-sand habitats presented higher species richness in undisturbed locations, where sessile groups such as sponges (Porifera) and soft corals (e.g. Pennatulacea) were predominantly found. In contrast, locations subjected to high disturbance showed lower diversity and high abundances of the dominant polychaete Hyalinoecia tubicula. The use of several biological traits (e.g. mobility, living habit, feeding type) will be discussed in relation to the community composition and structural diversity among the different habitats and disturbance pressures to better understand on the vulnerability of the continental slope benthic habitats.

Keywords: Epifauna communities, diversity, biological traits; sensitive species; EUNIS habitat, bottom trawling 